\title{
Effects of Self-Efficacy and Job Stress on Organizational Commitment among Clinical Dental Hygienists
}

\author{
Kyeong-Jin Lee and Young-im $\mathrm{Kim}^{\dagger}$ \\ Department of Dental Hygiene, Vision College of Jeonju, Jeonju 55069, Korea
}

\begin{abstract}
Background: This study aimed to provide basic data to establish a foundation for efficient operation of the organization by assessing the effects of self-efficacy and job stress (measured by self-efficacy, job demand, and job autonomy) on organizational commitment among clinical dental hygienists.

Methods: This was a cross-sectional survey study that used a self-administered questionnaire to collect data. After institutional review board approval, a survey was conducted from January to May 2017, targeting dental hygienists working in dental clinics and hospitals. The final 199 questionnaires were analyzed with PASW 18.0 for Windows (IBM Corp.). The data were analyzed using mean and/or standard deviation t-test, one-way ANOVA, and multiple regression analysis.

Results: The means for self-efficacy, job demand, job autonomy, and organizational commitment were $55.94 \pm 9.65,26.55 \pm 2.29,20.24 \pm 3.88$, and $49.49 \pm 8.39$, respectively. Along with self-efficacy, the other factors of organizational commitment among dental hygienists that were statistically significant included job autonomy, mean salary $(2,500 \sim 2,990$ thousand Korean won [KRW] and $\geq 3,000$ thousand KRW), and employee welfare (good), which are sub-areas of the surface acting. In other words, it was found that the higher the mean salary, the better the employee welfare, the higher self-efficacy, and the higher the organizational commitment, and the explanatory power of the model was approximately $42.1 \%$.

Conclusion: These results suggest that the higher the self-efficacy, job autonomy, mean salary, and employee welfare, the higher the organizational commitment. In order to improve job demand among dental hygienists, it is necessary to establish an effective plan to improve job welfare, self-efficacy, and job autonomy.
\end{abstract}

Key Words: Dental hygienist, Job stress, Self-efficacy

\section{Introduction}

In modern society, healthy living is becoming more important as the average life span is prolonged due to improvement in standard of living and the development of medical technology. Consequently, interest in oral health has increased along with interest in mental and physical health, and medical consumers have been demanding higher quality dental services as part of the continuing effort to maintain and improve their health ${ }^{1)}$. Therefore, dental hygienists, who contribute to the quality of dental services, are a key human resource; they can promote the survival and growth of a special type of organization called the dental medical institution ${ }^{2}$. Dental hygienists are clinical technicians; they are licensed professionals who support overall health through oral disease management and oral health promotion. In addition, an understanding of human beings and society through a systematic approach to dental hygiene knowledge and practice based on evidence is important. This understanding is achieved through training in the dental hygiene process, including assessment, diagnosis, planning, performance, and 
evaluation, which is the international standard of dental hygiene education for dental hygienists, and through competence in pursuing the goal of changing behaviors as well as promotion and prevention ${ }^{3)}$. Therefore, dental hygienists should adopt a proactive attitude toward the oral health problems of medical consumers. Doing so would aid the dental medical consumer in coping with the medical environment and actively participate in the decision-making process. This would also affect quality of life among dental medical consumers by improving their oral health. Dental hygienists could accomplish these aims as a competent professional manpower, through high intellectual levels and professional education ${ }^{4)}$. In dental medical clinics, the role of competent human resources, including dental hygienists, is important. The emotional well-being of the medical consumer is considered as well as his or her treatment and prevention. Therefore, it is important for dental hygienists to improve their selfefficacy. They must meet the medical consumer's need for healthcare professionals who can assume various roles and accomplish task in a rapidly changing medical environment, in addition providing high quality medical services. Self-efficacy refers to the belief in one's ability to successfully organize and carry out a series of behavioral processes to obtain certain outcomes. It refers to one's degree of self-confidence or one's confidence or belief in one's own competence as a dental professional, especially in specific situations ${ }^{5)}$. When self-efficacy is high, a proactive attitude is expressed improving one's own achievement and loyalty toward an organization, and it is expressed as an emotional response through the process of cognitive judgment about one's own ability to perform the given tasks well ${ }^{6}$.

In addition, hospital organizations that should provide medical services to medical consumers through mutual cooperation are more likely to have higher job stress than other occupations due to their business characteristics ${ }^{7)}$. In particular, dental hygienists have been reported to suffer from considerable job stress due to the burden of acquiring new knowledge and skills, heavy workload, high level of tension, unclear division of work, and attention ${ }^{8)}$. Therefore, it is very important to analyze organizational commitment among dental hygienists to promote organizational efficiency and exercise diverse competencies in the changing medical market. An important issue in dental management is how to secure excellent dental hygienists. It is important to create an environment and condition where they can work with a strong sense of belonging and attachment to their work organization and to lead them to be immersed in an organization in which they feel they belong ${ }^{9)}$. Therefore, the authors tried to understand the degree of job stress measured by self-efficacy, job demand, and job autonomy, among dental hygienists to promote the efficiency of dental medical organizations by testing a regulation effect of organizational commitment, and to provide basic data to establish plans to increase the organizational commitment of dental hygienists.

\section{Materials and Methods}

\section{Study subjects}

This study was conducted from January to May 2017, using structured questionnaires targeting dental hygienists working in dental clinics and hospitals located in Jeollabuk-do, Korea. The subjects were randomly sampled after their consent to participate in the study had been obtained. The total number of subjects was 204 when the minimum sample size was calculated after setting the significance level at 0.05 , the effect size at 0.15 , and the power at 0.95 using $\mathrm{G}^{*}$ power 3.1 software; however, 230 subjects in total were selected to minimize the sampling error as much as possible and in view of sampling bias and $10 \%$ dropout rate. Of the 230 questionnaires sent out, 199 questionnaires ( $86.5 \%$ recovery), excluding 31 questionnaires showing no responses and inadequate responses, were used for the final analysis.

\section{Study tools}

This study examined 14 self-efficacy questions, 11 job stress questions, 14 organizational commitment questions, and 7 job-related characteristics questions. For self-efficacy, a tool that had been modified for dental hygienists and used in a study by Kim et al. ${ }^{10)}$ was used in this study after the questions were modified and supplemented to match the purposes of this study. Each question was rated on a 5-point Likert scale, ranging from 5 ("strongly agree") to 1 
("strongly disagree"). The higher the score, the higher the self-efficacy. The reliability of this study was measured at Cronbach's $\alpha=0.924$.

For job stress, the investigator modified and supplemented a tool used by Kim et al. ${ }^{11)}$, through factor analysis and reliability analysis. The components of the questions consisted of sub-areas on job demand and job autonomy, ranging from 5 ("strongly agree") to 1 ("strongly disagree"). The higher the job demand, the higher the psychological burden of the job, and the higher the job autonomy, the higher the competency and level of authority in decision-making. The reliability for job demand was Cronbach's $\alpha=0.806$, and the reliability for job autonomy was Cronbach's $\alpha=0.638$.

For organizational commitment, the investigator modified and supplemented a tool used by $\mathrm{Gu}$ et al. ${ }^{12)}$, through factor analysis and reliability analysis. It consisted of 3 sub-areas (emotional commitment, continuous commitment, and normative commitment), and responses were based on a 5-point Likert scale, ranging from 5 ("strongly agree") to 1 ("strongly disagree"). The higher the score, the higher the organizational commitment. The reliability for organizational commitment was Cronbach's $\alpha=0.911$.

\section{Data analysis}

Data were analyzed using PASW 18.0 for Windows (IBM Corp., Armonk, NY, USA). The statistical significance level was 0.05. The subjects' self-efficacy, job stress, and organizational commitment were analyzed using mean and/or standard deviation. Organizational commitment as per the job-related characteristics of the subjects was tested using the t-test or analysis of variance, and the Scheffe test was used for post hoc testing. In order to examine the correlation between variables, analysis was conducted using the Pearson's correlation coefficient. Multiple regression analysis was used to determine the effect of organizational commitment on the relationship between the self-efficacy and job stress.

\section{Results}

1. Dental hygienists' self-efficacy, job stress, and organizational commitment

Results of the analysis of dental hygienists' selfefficacy, job stress, and organizational commitment are shown in Table 1. The overall mean of the subjects' self-efficacy and job stress were 55.94 and 46.79, respectively, and the job demand and job autonomy as subfactors were 26.55 and 20.24, respectively. The subjects' organizational commitment was 49.49, and for the subfactors, emotional organizational commitment was 21.34, continuous organizational commitment was 13.97 , and normative organizational commitment was 13.87 .

\section{Organizational commitment as per job-related characteristics of dental hygienists}

Results of the analysis of difference of organizational commitment per job-related characteristics of dental hygienists are shown in Table 2. Results indicate that the higher the monthly salary and the longer the total work experience, the higher the organizational commitment. Organizational commitment for current workplace experience between 5 and 9 years was the highest, and organizational commitment was higher in the absence of dental turnover experience. For the occupational type, the organizational commitment was highest in management/ administration, and it was found that the higher the organizational commitment, the higher the occupational level. For dental welfare, it was found that the better the welfare, the higher the organizational commitment.

Table 1. Analysis of Dental Hygienists' Self-Efficacy, Job Stress, and Organizational Commitment

\begin{tabular}{lc}
\hline \multicolumn{1}{c}{ Classification } & Value \\
\hline Self-efficacy & $55.94 \pm 9.65$ \\
Job stress & $46.79 \pm 5.20$ \\
Job demand & $26.55 \pm 2.29$ \\
Job autonomy & $20.24 \pm 3.88$ \\
Organizational commitment & $49.49 \pm 8.39$ \\
Emotional organizational commitment & $21.34 \pm 4.73$ \\
Continuous organizational commitment & $13.97 \pm 2.63$ \\
Normative organizational commitment & $13.87 \pm 2.69$ \\
\hline
\end{tabular}

Values are presented as mean \pm standard deviation. 
Table 2. Organizational Commitment as per Job-Related Characteristics of Dental Hygienists

\begin{tabular}{|c|c|c|c|c|}
\hline & \multirow{2}{*}{ Classification } & \multirow{2}{*}{$\mathrm{n}$} & \multicolumn{2}{|c|}{ Organizational commitment } \\
\hline & & & Mean \pm SD & $\mathrm{F}(\mathrm{p})$ \\
\hline \multirow{5}{*}{$\begin{array}{r}\text { Monthly salary } \\
(1,000 \mathrm{KRW})\end{array}$} & $\leq 1,490$ & 57 & $45.26 \pm 6.10^{\mathrm{a}}$ & $11.618(<0.001)$ \\
\hline & $1,500 \sim 1,990$ & 64 & $48.34 \pm 3.20^{\mathrm{ab}}$ & \\
\hline & $2,000 \sim 2,490$ & 35 & $52.03 \pm 6.01^{\mathrm{bc}}$ & \\
\hline & $2,500 \sim 2,990$ & 31 & $53.48 \pm 8.05^{\mathrm{bc}}$ & \\
\hline & $\geq 3,000$ & 12 & $58.00 \pm 7.03^{\mathrm{c}}$ & \\
\hline \multirow[t]{4}{*}{ Career (y) } & $<2$ & 54 & $45.72 \pm 6.17^{\mathrm{a}}$ & $10.721(<0.001)$ \\
\hline & $2 \sim 7$ & 51 & $47.49 \pm 6.48^{\mathrm{a}}$ & \\
\hline & $7 \sim 14$ & 45 & $52.49 \pm 9.88^{\mathrm{b}}$ & \\
\hline & $\geq 15$ & 49 & $52.98 \pm 8.59^{\mathrm{b}}$ & \\
\hline \multirow[t]{4}{*}{ Total work career (y) } & $<2$ & 74 & $46.82 \pm 7.27^{\mathrm{a}}$ & $10.126(<0.001)$ \\
\hline & $2 \sim 4$ & 55 & $47.89 \pm 7.10^{\mathrm{a}}$ & \\
\hline & $5 \sim 9$ & 41 & $54.24 \pm 8.78^{\mathrm{b}}$ & \\
\hline & $\geq 10$ & 29 & $52.62 \pm 9.24^{\mathrm{b}}$ & \\
\hline \multirow[t]{2}{*}{ Turnover experience } & No & 81 & $51.31 \pm 8.89$ & $2.475(0.011)$ \\
\hline & Yes & 118 & $48.25 \pm 7.82$ & \\
\hline \multirow[t]{3}{*}{ Dedicated work } & Medical practice & 73 & $47.34 \pm 7.75^{\mathrm{a}}$ & $6.736(0.001)$ \\
\hline & Medical practice and patient management & 92 & $49.71 \pm 7.54^{\mathrm{a}}$ & \\
\hline & Hospital management and administration & 34 & $53.53 \pm 8.35^{\mathrm{b}}$ & \\
\hline \multirow[t]{4}{*}{ Rank } & General dental hygienist & 141 & $48.10 \pm 7.77^{\mathrm{a}}$ & $5.183(0.002)$ \\
\hline & Team leader dental hygienist & 23 & $52.09 \pm 11.09^{\mathrm{a}}$ & \\
\hline & Chief dental hygienist & 31 & $53.22 \pm 7.60^{\mathrm{a}}$ & \\
\hline & Head dental hygienist & 4 & $57.00 \pm 2.31^{\mathrm{a}}$ & \\
\hline \multirow[t]{3}{*}{ Dental welfare } & $\mathrm{Bad}$ & 6 & $42.33 \pm 4.59$ & $10.108(<0.001)$ \\
\hline & Normal & 101 & $47.35 \pm 7.91$ & \\
\hline & Good & 92 & $51.87 \pm 8.27$ & \\
\hline
\end{tabular}

p-values by t-test or one-way ANOVA.

SD: standard deviation, KRW: Korean won.

a,b,c The same characters are not significant by Scheffe multiple comparison $(\mathrm{p}<0.001, \mathrm{p}<0.05)$.

Table 3. Correlation of Self-Efficacy and Job Stress with Organizational Commitment of Dental Hygienists

\begin{tabular}{|c|c|c|c|c|c|}
\hline \multirow{2}{*}{\multicolumn{2}{|c|}{ Classification }} & \multirow{2}{*}{ Self-efficacy } & \multicolumn{2}{|c|}{ Job stress } & \multirow{2}{*}{ Organizational commitment } \\
\hline & & & Job demand & Job autonomy & \\
\hline Self-effica & & 1 & & & \\
\hline \multirow[t]{2}{*}{ Job stress } & Job demand & $0.390 * *$ & 1 & & \\
\hline & Job autonomy & $0.356^{* *}$ & $-0.382 * *$ & 1 & \\
\hline \multicolumn{2}{|c|}{ Organizational commitment } & $0.457 * *$ & $0.299 * *$ & $-0.324 * *$ & 1 \\
\hline
\end{tabular}

$* * \mathrm{p}<0.001$ by Pearson's correlation analysis.

\section{Correlation of self-efficacy and job stress with} organizational commitment of dental hygienists

The correlation of self-efficacy and job stress with organizational commitment of dental hygienists is shown in Table 3. Organizational commitment showed statistically significant positive correlation with self-efficacy $(\mathrm{r}=0.457)$ and job autonomy ( $\mathrm{r}=0.299)$ (subfactors of job stress). In other words, the organizational commitment increased as the self-efficacy and job autonomy of job stress increased. However, it was found that there was a negative correlation between organizational commitment and job demand $(r=$ -0.324). In other words, the organizational commitment decreased as the organizational demand of job stress increased. 
Table 4. Factors Affecting the Organizational Commitment of Dental Hygienists

\begin{tabular}{lcccrr}
\hline \multicolumn{1}{c}{ Classification } & $\mathrm{B}$ & $\mathrm{SE}$ & $\beta$ & $\mathrm{t}$ & $\mathrm{p}$-value \\
\hline Self-efficacy & 0.354 & 0.057 & 0.421 & 9.168 & $<0.001$ \\
Job autonomy & 0.745 & 0.244 & 0.632 & 3.352 & 0.001 \\
Monthly salary $(2,500 \sim 2,990$ thousand KRW) & 0.209 & 0.063 & 0.396 & 2.849 & 0.003 \\
Monthly salary ( $\geq 3,000$ thousand KRW) & 0.310 & 0.115 & 0.271 & 2.683 & 0.001 \\
Dental welfare (good) & 0.290 & 0.060 & 0.342 & 4.880 & $<0.001$ \\
& \multicolumn{2}{l}{$\mathrm{R}^{2}=0.466$, adjusted $\mathrm{R}^{2}=0.421, \mathrm{~F}=39.881(\mathrm{p}<0.001, \mathrm{p}<0.05)$} & & \\
\hline
\end{tabular}

p-values by multiple regression analysis.

SE: standard error, KRW: Korean won.

\section{Factors affecting the organizational commitment of dental hygienists}

In order to investigate the factors affecting the organizational commitment of dental hygienists, jobrelated characteristics such as monthly salary, total work experience, current job, turnover experience, occupational type, position, and employee welfare were represented by dummy variables. With self-efficacy, job autonomy, and job demand of job stress as independent variables and the organizational commitment as a dependent variable, the results of the multiple regression analysis were as follows Table 4: The fitted regression model was statistically significant $(\mathrm{F}=39.881, \mathrm{p}<0.001)$, and the explanatory power of the model was $42.1 \%$. Self-efficacy $(\beta=0.421)$ and job autonomy $(\beta=0.632)$ of job stress as the selected independent variables had a statistically significant effect on organizational commitment. It was found that organizational commitment increased as self-efficacy and job autonomy of job stress increased. In addition, monthly salary $(\beta=0.396$ and $\beta=0.271$ ), and employee welfare $(\beta=0.342)$ all had a statistically significant effect on organizational commitment. Furthermore, it was found that organizational commitment increased when monthly salary was relatively higher and dental welfare was good.

\section{Discussion}

In order for dental hygienists to perform dental hygiene tasks positively and efficiently, they should be satisfied with their duties, and in order them to be satisfied with their duties, they should work in an optimal environment ${ }^{13)}$. They should provide high-quality services to medical consumers and grow into staff who can help the organization so that they can contribute to the achievement of the overall goal of dental hospitals/clinics ${ }^{3)}$. Creating an organizational culture that is capable of properly resolving potential conflicts in the organization and having a work life that promotes happiness in both life and work can enhance job commitment. Therefore, this study explored the factors of self-efficacy and job stress in order to determine which factors affect organizational commitment among dental hygienists and tried to provide the basic data to establish a foundation for efficient operation by increasing the organizational commitment of dental hygienists.

The self-efficacy of the subjects was high (55.94 out of 70 points). Jeung et al. ${ }^{14)}$ analyzed the relationship between self-efficacy perceived by dental hygienists and job commitment and found that the level of organizational commitment was significantly higher when self-efficacy was higher. Likewise, dental hygienists with high self-efficacy can be interpreted as having a high level of self-esteem and job commitment. Individuals with higher levels of self-efficacy conform to the purposes of their organization, are positively affected with regard to the performance of their work, and exhibit consistency in achieving goals when faced with external resistance ${ }^{15)}$; therefore, an efficient clinical education system focuses not only on dental tasks, but also on self-efficacy.

The overall mean for job stress was 46.79 , and the overall means for job demand and job autonomy as subfactors were 26.55 and 20.24 , respectively. In a study by Lee and Jung ${ }^{16)}$ on nurses, the overall means for job demand and job autonomy were 49.58 and 43.14, respectively, which were higher than those of dental hygienists. Due to the nature of the work, higher job 
demand scores indicate more psychological burden on the job, and higher job autonomy scores indicate that the individual has more authority in decision-making and is highly capable and competent. Therefore, this study suggests that psychological burden is higher in the various roles of dental hygienists in dental hospitals and clinics because job demand is higher than job autonomy. It is necessary to develop various programs that can relieve the psychological burden on the dental hygienist and to establish plans to increase organizational commitment by inspiring job efficiency and confidence.

Results of the analysis of difference of organizational commitment per job-related characteristics showed that the higher the monthly salary and the more total working experience, the higher the organizational commitment. The highest organizational commitment was among dental hygienists with work experience between 5 and 9 years in their current work place, and the organizational commitment was higher in the absence of dental turnover experience. With regard to dedication, dental hygienists in management/administration positions demonstrated the most dedication. Furthermore, the organizational commitment was high when the position of the dental hygienist was high and when he or she perceived that the dental welfare was good. In a study by Ryu ${ }^{17)}$, organizational commitment was high among individuals aged 31 years or older and in individuals with 11 years or more of work experience. In a study by Lee et al. ${ }^{18)}$, organizational commitment was high when the authorization of the dental hygienist (i.e., the level of factors such as competence, self-determination, influence, and meaningfulness) was high. In other words, because the organizational commitment of dental hygienists in dental hospitals and clinics can be a key factor in reducing the turnover rate and improving work performance, more management planning that increases work satisfaction and pride in one's organization and one's job performance is necessary.

As self-efficacy and job autonomy increased, organizational commitment also increased. However, as organizational demand increased, organizational commitment decreased. Kim et al. ${ }^{10)}$ suggested that self-efficacy has a positive effect on organizational commitment and that organizational commitment has a negative effect on turnover intension. These findings showed that selfefficacy, job autonomy, and job demand are important factors of organizational commitment among dental hygienists. Dental hygienist practice can be effectively improved in the future through continued training that focuses on organizational commitment and instills a sense of responsibility, increases competence, and is rewarding.

Monthly salary, welfare, self-efficacy, and job autonomy were also major factors of organizational commitment among dental hygienists. The fitted regression model was statistically significant, and the explanatory power of the model was $42.1 \%$. In addition, organizational commitment increased when monthly salary was high, dental welfare was good, self-efficacy was high, and job autonomy was high among the selected independent variables. Glisson and Durick ${ }^{19)}$ found that organizational commitment had a positive relationship with level of identity, importance, autonomy, functional diversity, and feedback, and had a strong negative relationship with work overload, work stress, role conflict, and role ambiguity. According to Steers $^{20)}$, the precedence factors of organizational commitment are distinguished into personal characteristics, job-related characteristics, and structural characteristics of the organization, and among these, the job-related characteristics are the most influential factors affecting organizational commitment ${ }^{20)}$. The organizational commitment of the dental hygienist will developed if the dental hygienist improves clinical practice through continuous and steady effort, and if a more rewarding and enriching working environment is created based on those efforts. In addition, it is crucial to establish organizational strategies to increase organizational commitment among dental hygienists.

The limitation of this study is that the data were not collected from dental hygienists in all regions. Therefore, it is somewhat unreasonable to expand the results of the study as a whole. In the future, to generalize the study results, it will be necessary to repeat the study by expanding the area and subject and employing various relevant tools. 


\section{Notes}

\section{Conflict of interest}

No potential conflict of interest relevant to this article was reported.

\section{Ethical approval}

This study was approved by the Wonkwang University Bioethics Review Committee (IRB No. W-201606-SB-031).

\section{ORCID}

Kyeong-Jin Lee, https://orcid.org/0000-0002-9159-4283

Young-im Kim, https://orcid.org/0000-0002-3926-5909

\section{Acknowledgements}

This research was supported by funds of Vision College of Jeonju.

\section{References}

1. Lee HS, Kim GS: Oral health behavior of economically active women in Chollabuck Do Republic of Korea. J Korean Acad Dent Health 23: 287-299, 1999.

2. Kim YS, Park HS: A study on work environment and job satisfaction of dental hygienists in Daegu and Gyeongsangbukdo. J Dent Hyg Sci 12: 600-606, 2012.

3. Kwon JY, Lee SY: Relationship of between task performance, job satisfaction, and organizational contribution of dental hygienists. J Dent Hyg Sci 16: 302-309, 2016.

https://doi.org/10.17135/jdhs.2016.16.4.302

4. Kim MJ, Lee HY, Kim YI: A study on the dental hygienists' image perceived by health allied college students. J Dent Hyg Sci 11: 481-487, 2011.

5. Bandura A: Self-efficacy mechanism in human agency. Am Psychol 37: 122-147, 1982.

6. Kang $\mathrm{OH}$ : The determinants of intent to leave of dental hygienists at dental clinics. J Dent Hyg Sci 6: 107-111, 2006.

7. Han AK, Kim OS, Won JS: A study on job stress and coping method by the personality types of clinical nurses. Clin Nurs Res 13: 125-136, 2007.

8. Kang HK, Kwun HS: A study on job satisfaction according to clinical dental hygienists' career in Busan. J Korean Acad Dent Hyg Educ 9: 507-521, 2009.
9. Kwon SJ, Bae SK: Analysis of impact factors of affective commitment in organization of dental hygienist in Busan area focused on Quality of Working Life (QWL). J Korea Content Soc 9: 156-165, 2009.

10. Kim HY, Choi JO, Seong MG: The effect of self-efficacy and job satisfaction of dental hygienists' on the organizational commitment and turnover intention. J Korean Soc Dent Hyg 12: 213-223, 2012.

11. Kim JJ, Roh JH, Won JU, Lee SY, Chang SJ: The relationship between occupational stress and burnout among occupational therapists. Korean J Occup Environ Med 22: 173-182, 2010.

12. Gu JY, Lim SR, Lee SY: Effects of organizational culture of dental office and professional identity of dental hygienists on organizational commitment. J Dent Hyg Sci 17: 516-522, 2017. https://doi.org/10.17135/jdhs.2017.17.6.516

13. Han JH, Song KS, Shin SJ: Factors affecting job satisfaction of clinical dental hygienists. J Dent Hyg Sci 18: 374-379, 2018. https://doi.org/10.17135/jdhs.2018.18.6.374

14. Jeung DY, Chang SJ, Noh HJ, Chung WG: Effects of educational training and psychosocial characteristics on job involvement in dental hygienists. J Dent Hyg Sci 15: 465-471, 2015. https://doi.org/10.17135/jdhs.2015.15.4.465

15. Maddux JE, Gosselin JT: Self-efficacy. In: Leary MR, Tangney JP, eds. Handbook of self and identity. Guilford Press, New York, pp.198-224, 2003.

16. Lee MK, Jung DY: A study of nursing tasks, nurses' job stress and job satisfaction in hospitals with no guardians. J Korean Acad Nurs Adm 21: 287-296, 2015. https://doi.org/10.11111/jkana.2015.21.3.287

17. Ryu HG: The correlation between the internal external satisfaction and organizational commitment of dental hygienist. J Korean Soc Dent Hyg 17: 735-745, 2017. https://doi.org/10.13065/jksdh.2017.17.05.735

18. Lee HK, Kim MJ, Lim YS: Dental hygienist, the relationship between empowerment and organizational commitment. J Korean Soc Dent Hyg 10: 645-654, 2010.

19. Glisson C, Durick M: Predictors of job satisfaction and organizational commitment in human service organizations. Adm Sci Q 33: 61-81, 1988. https://doi.org/10.2307/2392855

20. Steers RM: Antecedents and outcomes of organizational commitment. Adm Sci Q 22: 46-56, 1977. 